\title{
Chapter 13 \\ Field and Terrain: The Micropolitics of Community Leadership in Small, Rural Schools in England
}

\author{
Samantha H. Hillyard and Carl Bagley
}

\section{Introduction}

Our research focused upon the role of the school in two contrasting English village communities. We sought to explore the lived reality of rural spaces and places in the twenty-first century. ${ }^{1}$ Schools are often articulated as being at the "heart" of village life and we explored the veracity of this claim. The two villages were selected strategically to maximize the opportunities for comparison and contrast-one industrial and one more traditionally agrarian. This could offer the strongest prospect for rendering visible the normal, "white noise" of everyday life. The villages were:

Greenhow $^{2}$ a village with an agricultural heritage, a population of circa 600 and small village school (50 pupils) and;

Minbury: a village with a coal-mining heritage, a population of circa 2,000 and a village school (164 pupils).

We were theoretically influenced by Lefebvre (1991) and his work as applied to rural contexts (Halfacree, 2009). Rural space here is understood as a triptych of the material, imaginary, and practiced (Halfacree, 2007, p. 127). It captures that material space flows from both the tangible (material) world as well as from social constructions and action-based upon interpretations (practices and imaginary). This

\footnotetext{
${ }^{1}$ Supported by an UK Economic Social Research Council award (ESRC: RES-000-22-3412).

${ }^{2}$ Both village names are pseudonyms.
}

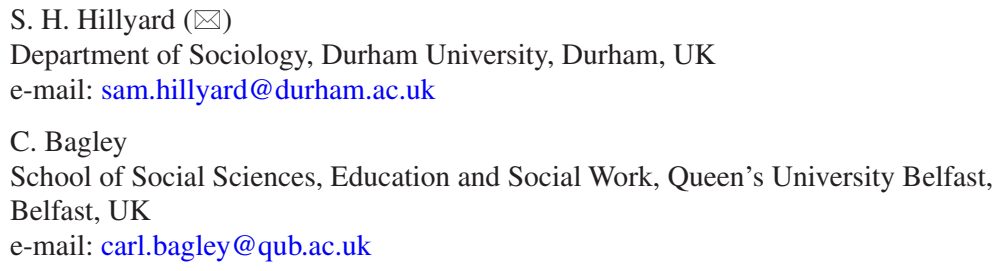


forces a rethink beyond purely geographic boundaries-it is hence both a bounded and boundary-less rural space. Halfacree (2007) usefully represents this as a triangular model with three facets:

- Rural localities inscribed through relatively distinctive spatial practices, linked to production and/or consumption activities

- Formal representations of the rural such as those expressed by capitalist interests, cultural arbiters, planners, or politicians

- Everyday lives of the rural, which are inevitably subjective and diverse, and with varying levels of coherence/fracture (Adapted from Halfacree, 2007).

Each is interconnected and folds into one another and all three facets together comprise rural space - the rural totality (Halfacree, 2007, p. 127).

Our approach to community extended and followed this understanding. Rather than being a geographically bounded locale, it too is part of a blurred rural community that does not perfectly correspond to a physical place. This is in keeping with rural studies that capture that rural areas are now highly differentiated. This "differentiated countryside" resists any ready essentialism being ascribed to rural localities (Murdoch, Lowe, Ward, \& Marsden, 2003).

Our methods were hence exploratory and open-ended, seeking to probe the meaning ascribed by actors in and around such locales. Our research was ethnographic and orientated towards verstehen and a rich, detailed understanding of each fieldwork site (Pole \& Hillyard, 2016). One fieldworker undertook the data collection in each village across a calendar year. In addition to our ethnographic dataset of observation and interviews, we also drew extensively on the archives and local documents available in each locale, such as parish records, school logs, and local newsletters. We were interested in power - that is, in how particular understandings of the situation and circumstances of each village were ascribed and operationalized. Using the research practice of ethnographic immersion, we followed the principle that "One cannot grasp the most profound logic of the social world unless one becomes immersed in the specificity of an empirical reality" (Bourdieu, 1993, p. 271).

Our approach therefore sits within the ethnographic research tradition, which is informed by an emphasis upon agency (Atkinson, 2015). In looking at the school, we encountered key roles that were institutionalized, in the sense that they were occupied by an individual, but more than the role alone. That is, some key roles in rural areas become embedded and inescapably central through the very rural context in which they are located. For example, in one village the head teacher had once also lived in the building adjacent to the school and been a key figure in the local village organizations (such as the Parish Council). This is, in part, because other organizations and institutions have dissipated.

We hence investigated the implications — and autonomy - for the individual situated in this rural, schooling, and locational context. As other institutional roles disappeared (such as shopkeeper, publican, or local doctor), did those remaining become more important? Both of our villages had retained their schools. We were therefore concerned with exploring the following questions: Was there something distinctive and tangible about the circumstances and role of a rural head teacher? What autonomy did they enjoy in their roles, and in what ways had these been curtailed under modernity? 


\section{Rural School Leadership}

The specialist literature on rural school leadership shared our interest and concern to understand the individual social actor in the context of place:

[There is] a complex socio-cultural politics to school leadership that is context specific and multi-layered ... a social practice that transcends the domain of being an individual's activity and can only be understood by getting up close to the culture of schooling and the social positioning of school leaders. (Eacott, 2010, p. 226)

In a contemporary, postindustrial economy, this is further layered into a modern bureaucracy. Often labeled neoliberalism within the contemporary literature (Greener, 2012), it situates any school leadership within the national policy framework within which they are working. This means that schools even in remote locales are impacted by external, national scrutiny. Gunter, Grimaldi, Hall, and Serpieri (2016) successfully captured the myriad layering of outside policy influences reaching into the contemporary rural school:

- Competition between schools is the new logic of educational activity.

- Ofsted ${ }^{3}$ inspects and grades schools according to school performance.

- School managers, as head teachers, are afforded responsibility for managing schools in line with performance indicators.

- National tests are established as key indicators of pupil, teacher, and school performance.

- Standards of attainment in relation to national testing are the benchmarks against which pupil, teacher, and institutional performance are judged.

- School-league tables are critical to local and national perceptions of school performance. (Adapted from Gunter et al., 2016)

A final, more specific but theoretical literature that is useful for making sense of the convergence of contemporary policy discourse upon individuals operating within that framework are a portfolio of ideas found within the work of Pierre Bourdieu.

\section{Engaging Bourdieu}

Engaging Bourdieu provides an opportunity to put Halfacree's (2009) abstract use of Lefebvre into practice and to explore how rural schools converge and translate neoliberalism. It enables a move-away from a normative reading of leadership towards one that acknowledges its temporal, complex, and situated nature-very much in keeping with Halfacree's (2007) triptych. It is vital here to see the individual actor in the local context, whilst appreciating the simultaneous interplay of both micro- and macrolevel forces in shaping practice.

Bourdieu's (1998) model serves to facilitate this. To draw upon Bourdieu's own terminology, school leaders engage in practices in a given field. More specifically,

\footnotetext{
${ }^{3}$ Office for Standards in Education, Children's Services and Skills.
} 
they draw on two interrelated resources - their habitus and forms of capital. This can be, and often is, represented in the following equation:

$$
(\text { habitus } \times \text { capital })+\text { field }=\text { practice }
$$

Adapted from Bourdieu, 1984, p. 101.

Bourdieu (1998) offered a rich array of theoretical concepts that positioned him as one of the leading scholars of his generation. Each concept is useful here:

Field: a structured system of social relations at the micro- and macrolevel, in which positions are defined relationally;

Habitus: a durable but transposable set of dispositions, representing the physical and mental embodiment of the social

A person's individual history is constitutive of habitus, but so also is the whole collective history of family and class that the individual is a member of;

Capital: (economic, cultural, social, symbolic) resource used to inform the habitus.

Critically for our interest here in specifically rural schooling contexts, he did not equate field with a physical locale. Rather, the field described a relationship, such as either centrifugal or repelling. Following Bourdieu's own advice to put concepts into empirical practice, we applied these concepts as a means to unlock our empirical data. We found the concepts of habitus and the reading of the field to be critical. That is, they mapped onto the understanding and articulations of the totalizing role that a modern school leader fulfills:

One minute you have a child who has fallen over in the playground and crying, at the same time as the phone rings and the local authority want to know about admissions and a parent in the corridor wanting to speak about her son's performance ... and decisions need to be made and documents signed, letters to go out, and this is all happening at once. (head teacher, Minbury Village)

There is a distinct kind of intensity to the rural head teachers' position. It folds many roles into one another, including their own delivery of teaching, the pastoral needs of the child and parent, and the logistical demands of neoliberal bureaucracy"everybody wears 27 hats" (head teacher, Greenhow School). So, whilst everyone working in a rural school faces intensity, the head teacher is exposed to external pressures at the forefront of their leadership role: "We have Ofsted, we have league tables, we have parents being able to choose their school, which means school competition, and in rural areas numbers are small and you are always conscious of the threat of closure" (head teacher, Minbury).

Similarly, within the second case study village, the very experienced Acting County head teacher did not view the question of closure optimistically in the long-term:

I don't think it will survive otherwise because I think you'll keep creaming off the top, all the time. And standards this year are dreadful. The SATS ${ }^{4}$ results that [the senior teacher] brought in — they're a particularly poor year going through but, increasingly, we are getting

\footnotetext{
${ }^{4}$ Key stage tests, commonly referred to as SATS.
} 
the bottom end of the market and that's going to make life really hard for [the incoming head teacher] and the teachers. (Head teacher, Greenhow village)

Here, space held a concentrating, intensifying effect. This applies not only to their own personal role (teacher/leader/administrator), but how the lack of population density means that the imposition of school choice is doubly felt here. Whilst parents may have only a limited choice (such as between two schools, whereas a more urban context may offer four), it holds definitive consequences. That is, for the school: success or closure. This is regardless of whether a school intake yearwhich may consist of only a handful of students-is exceptional or otherwise. The system becomes too blunt to capture such nuances.

After Bourdieu, we were keen to explore agency and the habitus and/or relative autonomy of head teachers within their locales. Our data began to reveal how head teachers' maneuvered, interpreted, and responded to such circumstances. It also offered scope for us to gain an insight into the individual agency they did and did not enjoy in the configuration of such spaces:

I consider myself to have a strong understanding of what needs to be done in order for this school to survive. Yes, number one, I want it to be part of the community and for families to feel welcome and see this as their local school, but of course I think that in trying to create that I hope it will mean them wanting to choose this school for their children. (Head teacher, Minbury Village)

Here, interests and concerns fold into one another. The head teacher is effectively playing her hand to the best advantage - that what could be seen as a threat (small size, small local pool of competition) could be reinvented to her benefit. So, the possibility of fostering a sense of community that a rural locale enables (perhaps more so than an inner-city environment) can be packaged and sold to the school's advantage - the community-feel of a small, rural school.

Distinctive to this head teacher was that she was then leading two primary schools through a shared headship across two schools - a federated approach. The federated strategy was not new, but that the schools both fell within the same geographic locale (i.e., village) was coincidentally highly beneficial for both the village and the head teacher:

I was aware that the authority was not keen to close schools and so a federated approach with me running both schools seemed like a sensible compromise. I see it as an opportunity, to try and work with a wider community, maybe even bring those communities together. I also didn't want the school to close or merge as I think it is important for the parents who live in Minbury Hill to keep their local school. The issues and problems are still the same, I guess Minbury Hill has greater social problems and issues but they are still deprived working class communities ... which is why I didn't want it to lose the school. (Head teacher, Minbury)

The geographic and class-based differences within Minbury (The Hill and the center of the village reflecting different social class occupancy) were echoed in the second village case study we introduce below. There are similarities in the closure of many other amenities (such as hostelries), but the economic decline was distinctive to Minbury. 
As our pseudonyms suggest, Minbury was a former coal-mining "pit" village. Closed in the 1960s, its urban proximity enabled it to become a commuting village and also retain a population of generational, long-term residents. This re-balancing was in transition during the fieldwork and a reflection of the differentiation countryside that Murdoch et al. (2003) described as postproductivist. Like our second village, Minbury was not the subject of the intensive gentrification experienced by villages such as those within the centrifugal pull of London (where second-home ownership has risen over $80 \%$ ). It was therefore at something of a crossroads, which was again intensified and doubly felt within the school. Namely, that in the absence of other constancy, what remained stable became all the more important:

The community has seen a lot of things close, you only need to drive through the village to see shops closed, houses boarded up, there is no work, there are very few places for the kids to go or do ... many end up unemployed or simply hanging around on the streets ... the school is one of the few constants ... and it was important for me to help keep it and try and use it in a way that was bigger than simply about reading and writing and numbers. (Head teacher, Minbury Village)

Minbury School provided examples that confirmed the models and concepts that both Halfacree (2009) and Bourdieu (1998) provide. The school was deeply embedded and affected by its past economic legacy, but also by (and increasingly so in the modern era) new manifestations of bureaucracy. Halfacree's triptych captures that representations of such spaces by those external to them hold increasing sway. Using Bourdieu, we were able to explicate how the head teacher was a key placement within the nexus or field. There was hence some capacity for their proactive interpretation and mediation of external pressures (such as school choice) to her advantage and own interpretation of the school's situation. This required drive:

To be a Head in a small school ... you've got to know when it's your moment, when it's your time. Because the demands on your time are massive. Because you haven't got somebody else who will be your senior teacher who will take assembly x times a week. Or, you're probably going to be in charge of special needs and literacy and the budget and risk, health and safety. Whereas, if you're in a big school, you've got two secretaries and a finance officer and a site manager. People in small schools, they get paid the lowest wage as a Head and they certainly earn their money. You might only be responding for 58 children and not 558 , but I think you work harder probably than the Head of a big school. (Head teacher, Greenhow Village)

In the following part of this chapter, we will now turn to further explore points of similarity and contrast.

\section{Greenhow: Livestock, Success, and Pavements}

The second village was not a pit village and agrarian interests were the key economic influence-although farming was less dominant than coal had been for Minbury (e.g., many parents worked outside agriculture). It was this-“modest" 
gentrifying - process that we found to be critical for its school and head teacher. That is, there emerged a challenge to recruit and retain a local school leader.

The comparison of Greenhow's situation with Minbury confirmed the value of a strategy of revealing insight through the striking differences generated across each village. A single study would not have offered such distinctions. Minbury was a former industrial village, whereas Greenhow was agrarian and continued to be primarily shaped and owned by farming families resident inside or nearby to the village. Greenhow was an old village, with a Saxon church and early available records indicating that it had remained at a consistent size (a population of circa 200) for centuries. However, there was a notable breach here, in that the village had expanded rapidly (more specifically, tripled in size) in the postwar period. It had been identified as capable of expansion in policy terms and the housing built during this period was highly varied, from social and council housing to large, detached executive homes. Building was furthermore ongoing during the period of fieldwork and further planning applications were under consideration.

In mining villages, local elites were rarely resident in the village itself. That is, the large Norfolk landowners of the era are often geographically distant. In Greenhow, there was no historic Lords of the Manor in the postwar period, as they had sold their landholdings. (They still owned the family's large estate house, a few villages away). In their absence, the continuity had been provided by the local, farming families. These were traceable through old Norfolk archives and directories, such as White's and Kelly's Trade Directories, which showed that four or so families had owned land in and around Greenhow for three to four generations. The presentday village was therefore an amalgam of both old and new residents, and the new residents further represented a diversity of household income reflected in very different patterns of residential occupancy-from homeowners to those in social housing who had not actively elected to live in the village:

Peculiar to here, is a very strange social arrangement in the village- the re-housing of people from ... from I suppose difficult circumstances, and all placed together in one place, there is a lot of unrest ... families who are here who are warring, I suppose, with a small 'w.' (Head teacher, Greenhow Village)

As in Minbury, the school was a remaining constant. In the late twentieth century, one of the village's two public houses (pubs) had closed, the village store had closed, but one opened on the periphery of the village nearer the access road. The village bakers and blacksmiths had closed up shop and the vicar was shared across other local churches. In sum, the postwar changes in Greenhow reflected those found in many English villages at the time, the end of what Newby (1977) termed the occupational community when agriculture provided the main source of local employment. Whilst not entirely removed, the farming families and those working in agriculture had been joined not just by new villagers, but by highly varied villagers and a type Greenhow would never have seen before-retired professionals from the South. Greenhow was an amalgam of newcomers, middle-class retired professionals buying off-plan, Norfolk locals able to afford the new housing coming onto the market, established farming families, and those in more temporary 
accommodation, who had not necessarily elected to live in the village, such as those assigned social housing in Greenhow by the council.

\section{The Resilience of the School}

The school was a constant-sustained and made possible by the new influx of village residents. Prewar, Greenhow's sister village had possessed the larger school, but was now increasingly eclipsed and gentrified, to the extent that its school had been amalgamated with Greenhow's primary school in the 1980s. This was reflected in a shifting school population (Table 13.1):

The school's own archives provided this level of information and detail to complement the ethnographic research. The head teacher's reflections-both in diaries and interviews - showed the changing status of the school leader, their position in the village, and their concerns. These can be summarized as: Space, infrastructure, and staff.

In the 1950-1980s, frequently cited concerns were pupil health (the provision of extra nourishment to some pupils and outbreaks of head lice) and the very built infrastructure of the school building itself. Built in the Victorian era, the school over the years acquired electricity, a telephone line, and (ironically for a rural school) eventually a playing field. New classrooms were as much a concern for the head teacher of the 1990s as of the 1940s.

In retrospect and in comparison to Minbury, the scale on which the head teacher had come to drive such initiatives, or intervene on their behalf, was remarkable. The school playing field was secured through the gift of a local landowner and initially only on loan. The new classrooms - replacing postwar "temporary" rooms-were only secured via an external grant competition. In this sense, they required an entrepreneurial head teacher:

It often depends on the Head about what that—what's that little bit of oofle dust, that little bit of sprinkle that makes your school different from somebody else's. And I think this school will get an identity with the new Head. (County head teacher, Greenhow Village)

The present day potentially posed the most challenging period the school had ever faced. The threat of closure, felt at Minbury, had been alleviated after the securing of the grant that significantly expanded and refreshed the school site. Following such work, the immediate threat of closure was removed. However, the records and contemporary fieldwork revealed very high patterns of staff turnover in the core teaching team. That is, whereas Minbury had a federated head, this was increasingly where matters were headed at Greenhow:

Table 13.1 Changing numbers on the school roll in Greenhow Village

\begin{tabular}{l|l|l|l|l|l}
\hline Year & 1912 & 1946 & 1949 & 1954 & 2011 \\
\hline No. on school roll & 66 & 31 & 100 & 136 & 58
\end{tabular}

Source: Design and data collection by author 
To be a Head in a small school you have to be completely ... well, you can't be selfish, you've got to be about other people. But equally you've got to know when it's your moment, when it's your time. Because the demands on your time are massive. Because you haven't got somebody else who will be your senior teacher who will take assembly x times a week. Or, you're probably going to be in charge of special needs and literacy and the budget and risk, health and safety. Whereas, if you're in a big school, you've got two secretaries and a finance officer and a site manager. People in small schools, they get paid the lowest wage as a Head and they certainly earn their money. You might only be responding for 58 children and not 558, but I think you work harder probably than the Head of a big school. I think it's more intense, because there's no-one to shield you from it. But, small school Heads do it differently. (County head teacher, Greenhow Village)

The sheer intensity of the role of the head teacher echoed the Minbury head's reflections. At Greenhow, this intensity was joined by a high turnover in staff, which included the head teachers themselves. Hence, during the fieldwork period alone, the temporary head teacher (who left to lead their own primary school) was replaced by an acting County Head (a head teacher shared by other school on a temporary basis, often associated with a school being placed in special measures). The turnover in teachers and how this had changed can also be further demonstrated. School records, such as press clipping retained from the local press in the school logs, show long-service awards for retiring staff (28 and 43 years, e.g.). Greenhow School had possessed a total of 22 heads, 11 of which had been acting. The last long-serving (10 years plus) head teacher had been appointed in 1991. This change was not immediately obvious without the point of contrast with Minbury and historical comparison. The pattern whereby the head stayed for over a decade and resided next door in School House (now a second-home) had effectively ended decades ago.

Bourdieusian ideas offer up an understanding of an actor within their cultural moment. In our case study schools, we identified an intensification in their role and the emergence of a correspondingly more entrepreneurial style of leadership. This cannot be explained entirely through the individual characteristics of the head teacher alone, but belongs to the Bourdieusian field, that is, the influential forces brought to bear by the wider society. As noted above, this includes modernity and neoliberalism. This can also be demonstrated by small, but subtle shifts or changes in language. In Greenhow, for example, the school managers became the governors (1980), the mothers and toddlers playgroup (est. 1985) turned into the pre-school group, and the Parents and Teachers Association (PTA) (est. 1952) became the Friends of the School (in 1981). In addition, outside actors imposed new regimes of metrics and evaluation.

In the UK system, these new metrics included the aforementioned Ofsted school inspections and national league tables. Greenhow School had, in living memory, excelled, securing national recognition as an example of excellence in the 1990s and this foregrounded the new building grant. However, this led to something of a trough after this peak. The new building was completed in the 2000s, but the governors and FoTS disbanded after large-scale resignations following a disappointing Ofsted, where the support and engagement of the Governors was criticized. The school logs capture the palpable disappointment of the then head-teacher. There was also a lack of "buy-in" from the present parent body. Collectively, this was something of a 
conflation and folding into one another of these shifts within the Bourdieusian field, but felt by the individual actors located there:

There has been too much change, so they can't trust anything any more. What am I? I'm the third Head in four terms, so next term [incoming new head teacher] will be the fourth Head in just over a year. And we all come in and we're all doing the same job, but we all do it differently. We all have different ways we want to do it and different ways that probably we engage with the parents and, like children, they just find it confusing. So, they're not particularly in tune with the school at the moment. (Head teacher, Greenhow Village)

The ethnographic data provided this wider insight into Greenhow School's own archives. They showed how two flows of impact affected the school. These were the ebbs and flows of the wider village as well as the cultural moment or policy disposition. Both were important. For example, the rural head teacher's autonomy from the community had shifted. What had been so successful in the 1990s, what respondents described as a somewhat insular school run as a "tight ship," had ended because it was no longer in keeping with the wider field:

All the other governors have had a few years of sitting back because she [long-term chair of the School Governors] has taken the reins and gone with it. But she's just resigned because she realizes that actually she has been doing too much ... [outgoing Chair of School Governors] did a really good job and she got a lot of things off the ground. I think she did it at personal cost to herself because she didn't delegate, or nobody was interested. I also think it possibly was at cost to a better working group. (Head teacher, Greenhow Village)

Indeed, the somewhat closed shop of the school had become inverted, as schools in the modern age were expected to become more interconnected with their local communities. Furthermore, the demographic shift within the village, which now included those coming into the village at the point of retirement, meant the school needed to look beyond its immediate vicinity for its catchment. Hence, at the time of the fieldwork, half of the school roll was from outside the village. Furthermore, the local competition faced by the school for its pupils placed it in competition with neighboring schools within what the England-Wales schooling system calls the local cluster (8-9 other schools in the vicinity). Collectively, the internal style of leadership in the 1990s had an isolating or insulating impact and the external shifts have meant that villagers lack a ready association with the school, despite the school becoming one of the few remaining amenities within the village. This was exacerbated by the village layout sitting within three general zones_-and the lack of pavements and footpaths connecting them. Collectively, something of the community cohesion had been lost. The acting County head teacher expressed her view that some of the parents negative memories of their own schooling: "I think a lot of them have had really poor experiences. So, get them in, show them ... actually what we do is quite good and it's jolly hard work" (Head teacher, Greenhow Village). Some parents thus felt disquiet even at the school gates.

The situation was further complicated by the factional or zoned layout and class differential found within the village as a whole mentioned above. This was tangible in Greenhow Village and the sense of collective support found in other villages was, in the eyes of Greenhow's acting head, absent here: 
[Elsewhere] they would look out for each other somehow, the parents. I mean these are real silly examples, but if there's a child whose mum hadn't quite arrived at the end of the day, you knew that whilst you had to make sure that it was alright for all the children to go with that parent and all that, but actually it wouldn't be a problem. There'd be a mum who'd be sitting on the playground with her own children and the child who'd been left playing a game with them while they were waiting for somebody to come. Whereas, here, they had a sort of oh so-and-so hasn't collected her child again — she's probably gone to bed or, you know, probably drunk or ... they're closed. It [the other village] felt very open. This is very closed. This has got a can't do mentality, so the village fete was cancelled, because it's run really by two or three mums, they're friends. The school fete, sorry, not the village, the school fete. Because they couldn't get any help from anybody.... Whereas, in Yorkshire, and other community schools I can think of, you knew that you'd only got to say to somebody, right, I'm a bit short of people for the cake stall or cakes, come one! And they'd go, oh yes, you told me three weeks ago, obviously I'll do it. But it always starts with a can't do here. Just a bit of negativity. (Head teacher, Greenhow Village)

Village cohesion could therefore not be explained by changes in the lack of amenities alone, nor by an expanding population. The notion of the field and its ability to capture this complexity will now be discussed and evaluated.

\section{Analysis: Engaging Bourdieu}

Becoming a school principal according to Bourdieu is then a slow and lengthy process of acquiring not only the symbolic and cultural capitals necessary for participation in the field, but also the processes of investing in the game, accepting its doxa and its ways of being, learning the strategies of participation, and acquiring the habitus, that embodied sense of being an administrator. (Thompson, 1999, p. 24)

Our results concur with the presence of a critical agency to be found within small school leadership. Particularly, that such agency is not always externally mediated:

Agency on behalf [of] head teachers should not necessarily be assumed to be 'individualis-
tic and competitive'. On the contrary 'choices have to be made about the kind of identity
and agency that players in the system want to aspire' as they strive to make strategic deci-
sions within a specific local context. There is struggle and conflict, as well as collaboration
and concord, as local terrains are shaped by myriad strategic and tactical decisions. (Woods
\& Simkins, 2014, pp. 336-337)

However, Greenhow Village revealed a particularly clear recruitment gap that showed that the sheer scale of the rural head's role had not been reflected in the present pay scales. Their cluster also comprised new head teachers who had only been in their posts for 2-3 years. The intensifying effect of being the head of a small, rural school thus put these teachers at the risk of burnout and contributed to a short period of leadership in their school. It constrained the kind of familiarization period with the local character and terrain that the Minbury head possessed and which informed her thinking. If habitus is acquired and adopted over time, this brevity has curtailed the scope or room for maneuvering the modern-day school leader enjoys. 


\section{Conclusion}

In this chapter, we have discussed the role and centrality of the school within two contrasting English rural villages. By studying two villages and their schools, we have begun to reveal the importance of each village's recent social histories for its school. That is, the school's resilience and sustainability-and even its very importance-were informed by historical change. Seeing the school relative to other village-based service provision and economic change enabled us to better understand the special intensity that some small schools face. Namely, in the absence of other institutions, they acquire greater significance and also the pressures of scale a small teaching team face logistically.

We have applied several theoretical ideas and concepts in this chapter that have enabled us to focus on and further explore the key actor of the small, rural school head teacher. We placed the head teacher within a Bourdieusian field that included (for our analysis) the terrain of a locale and its social history. Using the examples of two English rural villages, we discussed the head teacher as an actor in his or her context, and identified instances of both freedom and constraint. A key conclusion then is that the head teacher fulfills a mediating role. Theirs is, like that of midrange actors in other educational institutions such as universities (Deem, Hillyard, \& Reed, 2007), critical. However, rather than the rock-and-a-hard place situation that Deem et al. (2007) identified Heads of Department to occupy (between academics and senior management), head teachers here enjoyed greater professional autonomy. With this came intensity and pressure. Furthermore, the intensity of their workload was not recognized by present-day pay scales for small school leaders.

The question of the impact of the terrain was complex and multilevel. It advanced a Bourdieusian understanding of the field. Our empirical results based on ethnographic work in the two English villages allowed key differences to emerge. These were not merely between their economic legacy and history, but were strongly felt and influenced by present-day configurations. For both villages, this included strong class diversity amongst the village populations. Cultural heritages and individual leadership styles imprinted upon one another in both locales. The importance of a central school for Minbury in its postindustrial context and, in Greenhow, how the lack of community engagement both reached into the presentday relations found in both schools. The chapter therefore showed a very social reading of the terrain, but one that injected space into the Bourdieusian field.

In this chapter, we have argued that the relative autonomy of the rural head teacher as a key actor in a small rural community has shifted, as has the relationship between the school and village social cohesion. The backdrop of the cultural heritage of both locales proved vital, because they were mutually informing. This confirmed Halfacree's (2007) model using the ideas of Lefebvre-space/people and representations are a triptych and fold into one another-and offers a more sophisticated understanding of contemporary rural contexts.

A key finding of the chapter is therefore that the individuals-such as head teachers-and the small rural schools within which they function are within a field, 
which here serves as a centrifugal and repelling force. Our findings suggest that neoliberalism has extended the reach of this force and that the relative autonomy of a head teacher has declined. Although some individual agency or autonomy remains, it is restricted in the modern-day context by the intensity of the role, which has led to a short-termism. This curtails the small, rural school head teacher's opportunities to "ground" or familiarize themselves with the terrain and cultural heritage of their locale. The field must be understood to also include the triptych of rural spaces.

In contemporary debates about school resourcing, it seems unlikely that greater public funding will flow into small schools. The very viability of these institutions is therefore in question - will rural areas continue to see the pattern of de-development found in both case study locales examined here? Hence, the time at which a "tipping point" of no return is reached merits further investigation, which would ask after the repercussions for rural spaces when key institutions such as schools are lost, and the consequences of the de-development or unravelling of modernity in rural spaces.

\section{References}

Atkinson, P. (2015). For ethnography. London, UK: Sage.

Bourdieu, P. (1984). Distinction: A social critique of the judgement of taste. Cambridge, MA: Harvard University Press.

Bourdieu, P. (1993). Concluding remarks: For a sociogenetic understanding of intellectual works. In C. Calhoun, E. LiPuma, \& M. Postone (Eds.), Bourdieu: Critical perspectives (pp. 263-275). Cambridge, UK: Polity.

Bourdieu, P. (1998). Practical reason: On the theory of action. Stanford, CA: University Press.

Deem, R., Hillyard, S., \& Reed, M. (2007). Knowledge, higher education, and the new managerialism: The changing management of UK universities. Oxford, UK: Oxford University Press.

Eacott, S. (2010). Studying school leadership practice: A methodological discussion. Issues in Educational Research, 20, 220-233. Retrieved from http://www.iier.org.au/iier20/eacott.pdf

Greener, I. (2012). Public management (2nd ed.). Basingstoke, UK: Palgrave Macmillan.

Gunter, H. M., Grimaldi, E., Hall, D., \& Serpieri, R. (2016). NPM and educational reform in Europe. In H. M. Gunter, E. Grimaldi, D. Hall, \& R. Serpieri (Eds.), New public management and the reform of education: European lessons for policy and practice (pp. 3-18). Abingdon, UK: Routledge.

Halfacree, K. (2007). Trial by space for a 'radical rural:' Introducing alternative localities, representations and lives. Journal of Rural Studies, 23, 125-141. https://doi.org/10.1016/j. jrurstud.2006.10.002

Halfacree, K. H. (2009). Urban-rural continuum. In R. Kitchin \& N. Thrift (Eds.), International encyclopedia of human geography (Vol. 1, pp. 119-124). Amsterdam, The Netherlands: Elsevier.

Lefebvre, L. (1991). The production of space (D. Nicholson-Smith, Trans.). Oxford, UK: Blackwell.

Murdoch, J., Lowe, P., Ward, N., \& Marsden, T. K. (2003). The differentiated countryside. Routledge Studies in Human Geography. Vol. 3. London, UK: Routledge.

Newby, H. (1977). The deferential worker. Harmondsworth, UK: Penguin.

Pole, C. J., \& Hillyard, S. (2016). Doing fieldwork. London, UK: Sage. 
Thompson, P. (1999). Reading the work of school administrators with the help of Bourdieu: Getting a 'feel for the game'. Retrieved from http://www.aare.edu.au/data/publications/1999/ tho99060.pdf

Woods, P., \& Simkins, T. (2014). Understanding the local: Themes and issues in the experience of structural reform in England. Educational Management Administration \& Leadership, 42, 324-340. https://doi.org/10.1177/1741143214521587

Open Access This chapter is licensed under the terms of the Creative Commons Attribution 4.0 International License (http://creativecommons.org/licenses/by/4.0/), which permits use, sharing, adaptation, distribution and reproduction in any medium or format, as long as you give appropriate credit to the original author(s) and the source, provide a link to the Creative Commons license and indicate if changes were made.

The images or other third party material in this chapter are included in the chapter's Creative Commons license, unless indicated otherwise in a credit line to the material. If material is not included in the chapter's Creative Commons license and your intended use is not permitted by statutory regulation or exceeds the permitted use, you will need to obtain permission directly from the copyright holder.

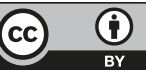

